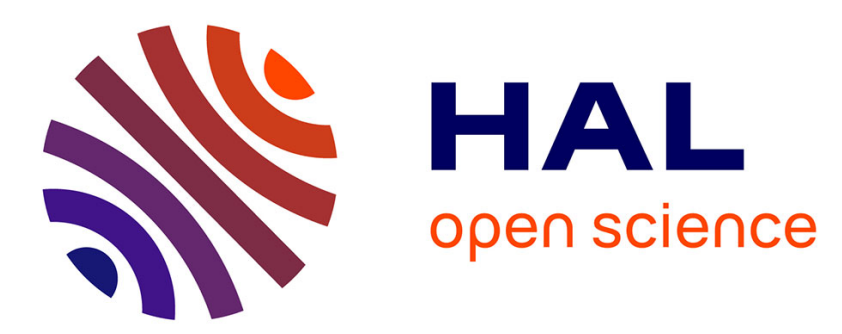

\title{
A criterion to discriminate between solar and cosmic ray forcing of the terrestrial climate
}

\author{
H. Fichtner, K. Scherer, B. Heber
}

\section{To cite this version:}

H. Fichtner, K. Scherer, B. Heber. A criterion to discriminate between solar and cosmic ray forcing of the terrestrial climate. Atmospheric Chemistry and Physics Discussions, 2006, 6 (5), pp.10811-10836. hal-00302233

\section{HAL Id: hal-00302233 \\ https://hal.science/hal-00302233}

Submitted on 25 Oct 2006

HAL is a multi-disciplinary open access archive for the deposit and dissemination of scientific research documents, whether they are published or not. The documents may come from teaching and research institutions in France or abroad, or from public or private research centers.
L'archive ouverte pluridisciplinaire HAL, est destinée au dépôt et à la diffusion de documents scientifiques de niveau recherche, publiés ou non, émanant des établissements d'enseignement et de recherche français ou étrangers, des laboratoires publics ou privés. 
Atmos. Chem. Phys. Discuss., 6, 10811-10836, 2006 www.atmos-chem-phys-discuss.net/6/10811/2006/

(c) Author(s) 2006. This work is licensed under a Creative Commons License.

Solar or cosmic ray climate forcing?

\title{
H. Fichtner et al.
}

\section{A criterion to discriminate between solar and cosmic ray forcing of the terrestrial climate}

\author{
H. Fichtner ${ }^{1}$, K. Scherer ${ }^{1}$, and B. Heber ${ }^{2}$ \\ ${ }^{1}$ Institut für Theoretische Physik IV, Ruhr-Universität Bochum, 44780 Bochum, Germany \\ ${ }^{2}$ Institut für Experimentelle und Angewandte Physik, Christian-Albrechts-Universität Kiel, \\ 24118 Kiel, Germany
}

Received: 15 August 2006 - Accepted: 19 October 2006 - Published: 25 October 2006

Correspondence to: H. Fichtner (hf@tp4.rub.de)

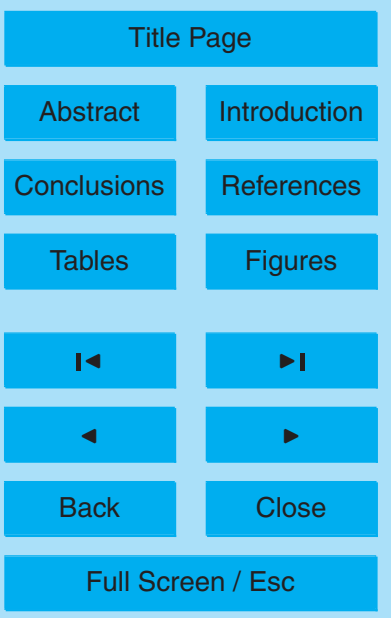

Printer-friendly Version

Interactive Discussion 


\section{Abstract}

There is increasing evidence that there exist interstellar-terrestrial relations and that the heliosphere's effectivity to serve as a protecting shield for the Earth, specifically against cosmic rays, is varying in time. Nonetheless, a debate is going on whether,

5 amongst other drivers, the Sun or the cosmic rays are influencing the terrestrial climate, particularly on periods of hundred years and shorter. As the modelling of the transport of cosmic rays in the heliosphere has evolved from pure test particle simulations to far more consistent treatments, one can explain various correlations within the framework of physical models and one can make quantitative predictions regarding terrestrial indicators of interstellar-terrestrial relations. This level of understanding and modelling allows to identify a criterion with which one can discriminate between solar and cosmic ray forcing on a period of several decades. We define such a criterion and discuss related existing observations.

\section{Introduction}

15 Two of the presently exciting fundamental question in space physics are: Is the terrestrial climate influenced by extraterrestrial drivers? and if so: What is the main extraterrestrial climate driver?

In view of almost overwhelming evidence the answer to the first question is positive. Correlations of the temperature on Earth with the 11-year Schwabe cycle of solar activity (e.g., van Loon and Shea, 2000), with the so-called grand minima of solar activity (e.g., Eddy, 1976; National Research Council, 1994), with the Milankovitch periods (e.g., Olsen and Kent, 1999), with geomagnetic field reversals (e.g., Christl et al., 2004), and with the galactic spiral arm crossings of the Sun (Shaviv and Veizer, 2003) have been found. These correlations are valid on time scales of tens, hundreds, hundred thousands and millions of years, respectively. We do not intend to enter a discussion of the credibility of any given correlation, because the mere proof of its existence will not

Solar or cosmic ray climate forcing?

\section{H. Fichtner et al.}

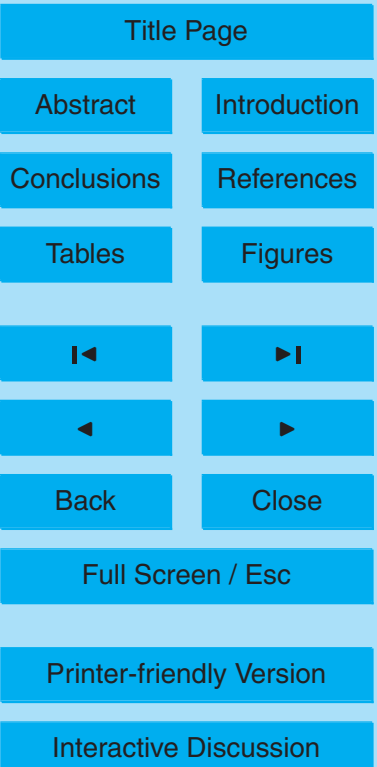


give too much insight into its actual physical cause. We are convinced, however, that not all proposed correlations are wrong, and that, therefore, the extraterrestrial climate driving is real.

The second question is far more difficult to answer. In this paper we concentrate on 5 the significance of solar activity for climate forcing, because there is certainly evidence that it plays an important role. It is, however, unclear whether this climate driving is direct or indirect, i.e. whether it is influenced by the solar irradiance or via another agent. A potential candidate are cosmic rays because also the flux of these high energy particles is subject to activity variations, too. A clarification can only arise from the 10 combination of a clearcut proof of existence of a given correlation and the connection of the latter to one or more physical processes. Presently, there are two main streams. One favours direct solar forcing as a result of an 11-year variation of the solar irradiance as displayed in the upper panel of Fig. 1. Evidently, the solar irradiance is quasiperiodically varying by about $2 \mathrm{~W} / \mathrm{m}^{2}$, i.e. about $1.5 \%$, which one could expect to have 15 a direct effect on the Earth climate. The other prefers indirect solar forcing via cosmic rays, because their flux appears to be correlated with the global coverage of Earth with certain cloud types, see the lower panel in Fig. 1. According to that idea the cosmic ray-induced $2-3 \%$ variation of the terrestrial cloud cover is influencing the climate.

Unfortunately, as reviewed in Rind (2002), both ideas face difficulties. On the one hand it is unclear whether the changing energy deposition as a result of irradiance variations in the $0.1-0.2$ percent range can have the proposed effect on the terrestrial climate system. On the other hand, severe criticism has been formulated regarding a link between cosmic rays and clouds as well as the process of cloud formation, although observational evidence for the latter appears to be growing, see, e.g., Harrison and Stephenson (2005) and references therein. It appears to us that the present deadlock in the debate can only be removed by an unambiguous discrimination based on a study of time scales longer than the Schwabe cycle.

For very long periods as analyzed by Shaviv and Veizer (2003), solar activity is very unlikely to play a role. Consequently, a confirmation of the claimed correlation between

Solar or cosmic ray climate forcing?

H. Fichtner et al.

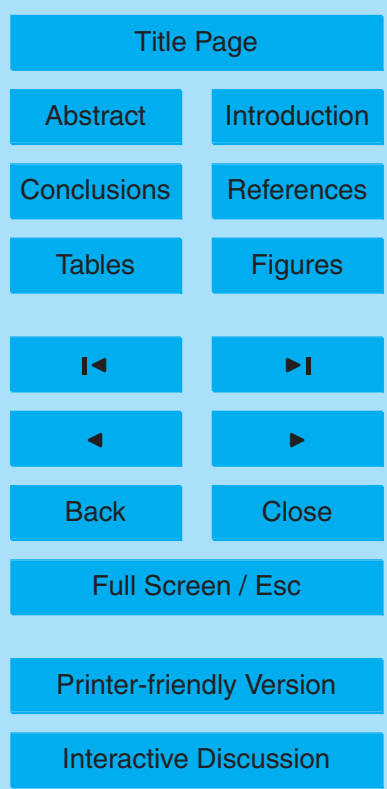

EGU 
terrestrial temperature and spiral arm crossings of the Sun would clearly support the cosmic ray driving. But, besides the fact that an unambiguous proof will be very difficult for many reasons such as large error bars for all related measurements, it would only hold true for this very long time scale. Similar arguments can be made for the typical 5 time scale of geomagnetic field reversals; and the discussion of the climate during grand minima faces the same difficulty as that for the Schwabe cycle: solar irradiance and cosmic ray forcing work the same way, see, e.g., Caballero-Lopez et al. (2004); Scherer and Fichtner (2004).

This leaves us with a study of the 22-year activity or so-called Hale cycle, i.e. a 10 pair of two consecutive Schwabe cycles that differ in the polarity of the solar magnetic field. We argue that on this time scale a clearcut discrimination between the two climate drivers is possible because cosmic ray driving should result in a distinct 22-year climate signal while solar irradiance forcing should not. Given the comparatively short period, available climatological, hydrological, and geophysical data allow to test this criterion.

15 After a presentation of the main argument we, therefore, also discuss the outcome of such tests.

\section{The 22-year cycle}

It is well known that any two consecutive 11-year cycles of solar activity are characterized by an opposite polarity of the solar magnetic field. Therefore, it makes sense to distinguish the 11-year activity (Schwabe) cycle from the 22-year magnetic (Hale) cycle. The response of solar irradiance and cosmic ray fluxes to these fundamental (Valdes-Galicia et al., 2005) periods is different as is described in the following.

\subsection{Significance for the solar irradiance}

The solar irradiance clearly shows an 11-year variation, see Fig. 1. During maximum activity it is about $2 \mathrm{~W} / \mathrm{m}^{2}$ higher than at times of solar minimum. So far, it appears

Solar or cosmic ray climate forcing?

H. Fichtner et al.

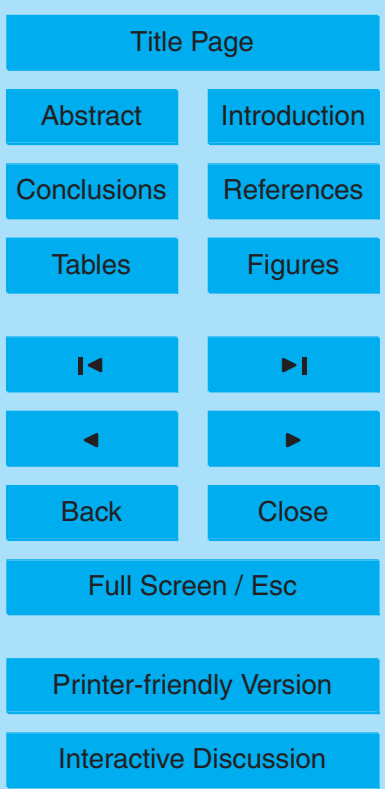

EGU 
that there does not exist a 22-year period in the irradiance variation, as neither the maxima nor the minima of solar activity show a significant corresponding pattern, see, e.g. Fligge and Solanki (2000). This observation is not simply a result of the difficult situation regarding the data and their cross-calibration between various instruments,

5 see Fig. 2. From the data shown in that figure it is obvious that composites of the various irradiance measurements as, for example, the one given in the upper panel of Fig. 1, cannot be obtained straightforwardly.

More serious than this uncertainty regarding the measurements is the principal argument that the irradiance variation should be related to the changing strength and 10 structure of the solar magnetic field but not to its polarity. A dependence on the magnetic polarity would rather be surprising because no physical process providing such a relation has as yet been identified. And, even if such process would be found, the presently available observations strongly suggest that the link between the 22-year cycle to solar irradiance variations must be very weak.

\subsection{Significance for cosmic ray fluxes}

The cosmic ray fluxes exhibit, in stark contrast to the irradiance variation, a very clear dependence on the 22-year magnetic cycle, see Fig. 3, showing in the top panel data from a ground-based neutron monitor, in the middle the measurements made with the IMP, the ACE and the Ulysses (KET) spacecraft, and in the bottom panel the sunspot 20 number. The 22-year cycle is manifest in the less and more peaked flux maxima, which are very pronounced in the neutron monitor data, and also clearly visible in the cosmic ray ion and electron data in interplanetary space.

The presence of the Hale cycle in these data is easily explained with the present paradigm of cosmic ray transport in the heliosphere. It is based on the so-called Parker 25 transport equation (Parker, 1965) that quantitatively describes the evolution of the (differential) cosmic ray flux $j(\boldsymbol{r}, p, t)=p^{2} f(\boldsymbol{r}, p, t)$ as a function of location $\boldsymbol{r}$, momentum

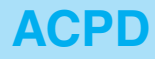

6, 10811-10836, 2006

Solar or cosmic ray climate forcing?

H. Fichtner et al.

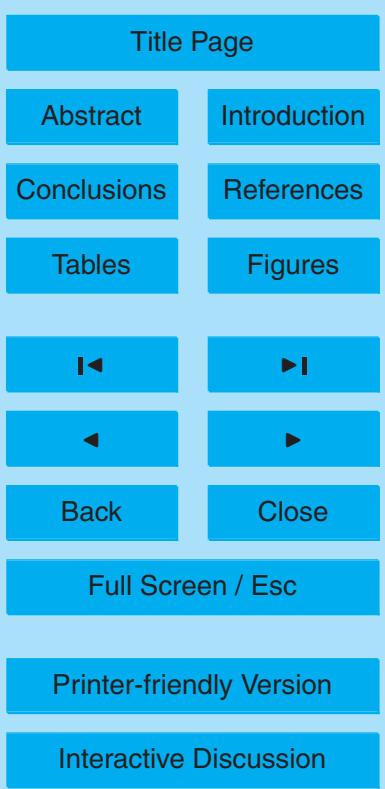


$p$, and time $t$ :

$\frac{\partial f}{\partial t}=\nabla \cdot(\overleftrightarrow{\kappa} \nabla f)-\boldsymbol{v}_{s w} \cdot \nabla f-\boldsymbol{v}_{d r} \cdot \nabla f+\frac{p}{3}\left(\nabla \cdot \boldsymbol{v}_{s w}\right) \frac{\partial f}{\partial p}+S(\boldsymbol{r}, p, t)$

ACPD

The terms on the right-hand side determine four physical processes, namely the spa-

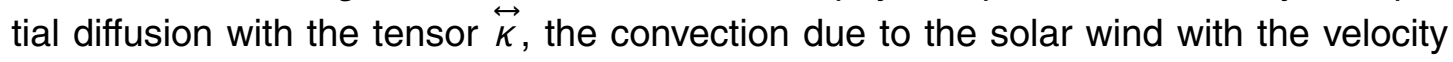
$5 \boldsymbol{v}_{s w}(\boldsymbol{r}, t)$, the gradient and curvature drift in the heliospheric magnetic field with the velocity $\boldsymbol{v}_{d r}(\boldsymbol{r}, p, t)$, and the adiabatic energy changes with the velocity divergence $\nabla \cdot v_{s w}$. Local particle sources could be included by adding a source term $S(r, p, t)$ to the righthand side. There is general well-founded consensus that this transport equation for high energy particles is complete (Fisk, 1999), so that the main task of so-called cos-

10 mic ray modulation models is nowadays the determination of the transport parameters and their variation in phase space and in time.

In the present context it is particlularly important to note how the transport processes depend on the solar/heliospheric magnetic field $B(r, t)$. The solar wind velocity and, therefore, convection and adiabatic energy changes, are independent of the magnetic 15 field. The parameterization of the diffusion tensor in terms of the field magnitude $B=|B|$ has been highly successful in the modelling of the fluxes of various cosmic ray species, see, e.g., Ferreira and Potgieter (2004). Only the drift velocity is depending on the field orientation:

$\boldsymbol{v}_{d r} \propto q \nabla \times B / B^{2}$

20 where $q$ denotes the particle charge, see, e.g., Isenberg and Jokipii (1979). Exactly this dependence imprints the 22-year cycle on the cosmic ray fluxes: the changing polarity of the solar magnetic field, which forms in combination with the expanding solar wind the heliospheric magnetic field, implies a sign change of the drift velocity.

This relation of the drift process to the magnetic field orientation is illustrated in Fig. 4.

25 Traditionally, the two subcycles are labeld with $q A$, where $A>0(A<0)$ corresponds to a solar or heliospheric magnetic field pointing away from the Sun in its northern (southern) hemisphere.

Solar or cosmic ray climate forcing?

H. Fichtner et al.

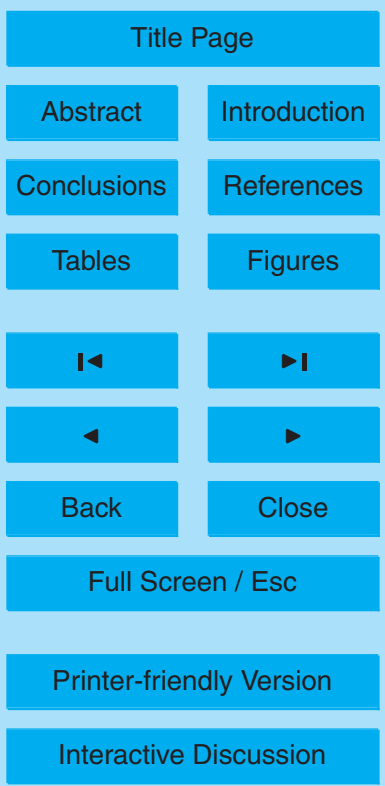

EGU 
The drift effect manifests itself in the long-term variations of cosmic rays including a change in their energy spectra. The typical flux maxima of nuclei (electrons) during solar activity minima are less (more) peaked for an $A>0$ subcycle and vice versa for an $A<0$ one, see the middle panel of Fig. 3. The changing spectra are implied by

5 the different peak heights, as indicated by the horizntal lines in the top and middle panel. It is evident from the opposite behaviour of positively and negatively charged particles that the drift effect is real and indeed having the principal dependences on field orientation and particle charge as given with expression (2).

The peaked and flat tops of the proton flux maxima observed in space are also visible 10 in the ground-based neutron monitor measurements shown in the top panel in Fig. 3. These flux variations are direct evidence for the 22-year cycle in cosmic ray fluxes and are a first indication for the presence of this cycle in the Earth's atmosphere. It is important to note that this presence of the 22-year cycle in the atmospheric fluxes of energetic particles imply that neither the magnetosphere nor the (higher) atmosphere can prevent these flux variations to be observed with ground-based instruments.

The question is now whether there are further indicators of the presence of the 22year cycle in the Earth's atmosphere and possibly on the terrestrial climate.

\section{A 22-year signal in cosmogenic isotopes}

According to the general understanding of how cosmogenic isotopes are produced in the atmosphere of the Earth (see, e.g., Beer, 2000), their concentrations should exhibit both an 11- and a 22-year cycle. While the former has been found in numerous time series of both ${ }^{10} \mathrm{Be}$ and ${ }^{14} \mathrm{C}$ concentrations (Beer, 2000), significance for the latter has been found only recently by Miyahara et al. (2005) from the analysis of Japanese cedars trees. Results obtained by the first group are given in Fig. 5, giving in the 25 upper panel the ${ }^{14} \mathrm{C}$ record during the Maunder Minimum and in the lower panel the band-pass filtered ${ }^{14} \mathrm{C}$ data compared to the sunspot number.

This can be regarded as direct evidence for the expected presence of the 22-year

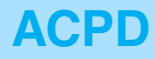

6, 10811-10836, 2006

Solar or cosmic ray climate forcing?

H. Fichtner et al.

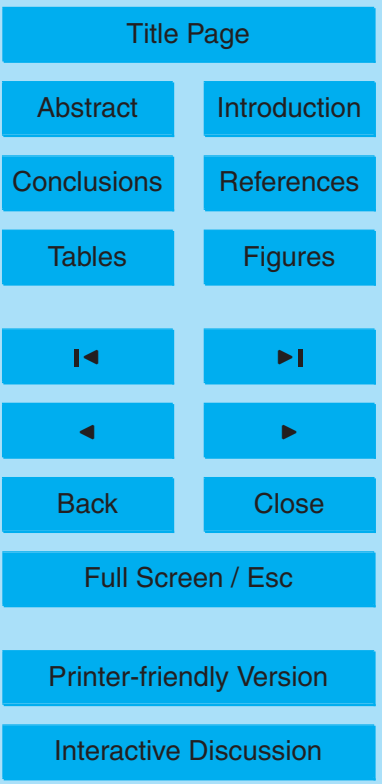


cycle in cosmogenic isotope data. First, this is a satisfactory observation giving further support for the present paradigm of cosmic ray transport in the heliosphere. Second, it indicates that the solar/heliospheric magnetic field had indeed "normal" reversals during the Maunder Minimum, a question that has been debated recently (e.g., Makarov

5 and Tlatov, 2000). It does not, however, imply any climate response, because cosmogenic isotopes are just passive tracers of the cosmic ray flux entering the terrestrial atmosphere. Therefore, one must search for the 22-year period in climate indicators.

\section{Is there a 22-year signal in climate indicators?}

\subsection{Clouds}

10 If the proposed cosmic ray-cloud correlation is real, the 22-year cycle should show up in the cloud data as well. Marsh and Svensmark (2003) extended the correlation analysis shown in Fig. 1, a result is given in Fig. 6.

Obviously, the cloud data show the expected behaviour, i.e. a change from a peaked maximum in 1987 to a flat one in 1997 . But also clouds are no direct climate indica15 tor and the implications of the determined variation for the terrestrial climate remain unclear for the time being.

\subsection{Width of tree rings}

Murphy et al. (1994), Raspopov et al. (2004) and Rigozo et al. (2005) report about studies of the periodicity of climatic processes in Colorado, along the Russian Arctic Ocean coast and the Chilean coast, respectively. They analyzed the tree ring width chronologies for these regions. As the most recent example, Fig. 7 gives the results obtained by Rigozo et al. (2005), who applied a multiple taper method to the time series of the tree ring width.

As can be seen from this figure, there is strong evidence of a 22-period in tree ring width in addition to an 11-year signal. Obviously, the growth of tree rings is connected

Solar or cosmic ray climate forcing?

\section{H. Fichtner et al.}

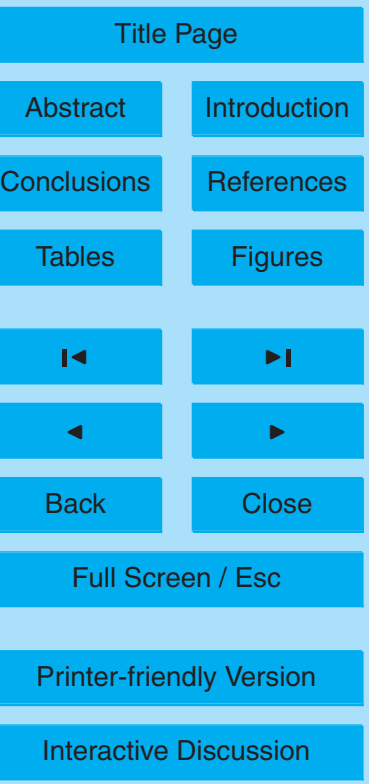


to climate, e.g. to precipitation. Therefore, it is worthwile to check whether rainfall times series also show both periods.

\subsection{Rainfalls and droughts}

While it is certainly very difficult to obtain reliable data there is evidence not only for the

5 11- but also for the 22-year cycle in rainfall. For a general correlation of rainfalls with the solar activity see Stager et al. (2005), who analysed the levels of Lake Victoria, East Africa, and found clear indications for a correlation.

Regarding the 22-year period Zhao et al. (2004) by using continuous wavelet transform examined relationship between the annual precipitation in the Beijing area and solar activity, see Fig. 8.

Their results clearly show an 11- and 22-year period in the precipitation data (upper panel of Fig. 8), while the latter period is rather weak in the sunspot number. This indicates not so much a correlation of sunspots or solar irradiance to the 22-year period of the rainfalls, but rather - in view of the natural 22-year variation of cosmic ray intensity - to a cosmic ray-climate connection.

We are well aware that not all precipitation data are containing the 11-year period that is nicely seen above, see, e.g. Alexander (2005). The absence of an 11-year period might be caused by data of poor quality like in Alexander (2005) or might arise from a variety of local causes (Murphy et al., 1994).

20 Another, also still debated, manifestation of the 22-year cycle is a drought pattern in the western United States (Mitchell et al., 1979). Perry (2005) gives an updated overview regarding the droughts and also regarding floods related to the Mississippi river, and it appears that the 22-year cycle is indeed present in the data.

The relative importance of the 22-year and 11-year cycles has also been discussed 25 by Burroughs (2004), who gives further evidence for a strong 22-year cycle in many data series.

Solar or cosmic ray climate forcing?

\section{H. Fichtner et al.}

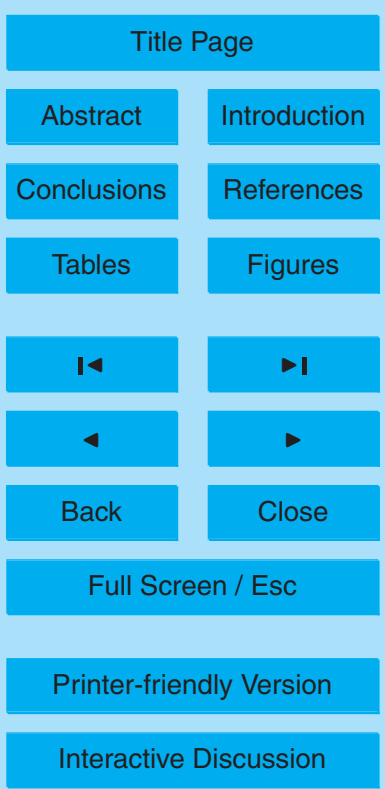




\subsection{Glacio-chemicals}

Another signal comes from the glacio-chemical record from the east-antarctic Princess Elizabeth Land. (Xiao et al., 2004) analyzed the sodium $\left(\mathrm{Na}^{+}\right)$record archived in ice cores extracted from the Lambert Glacier Basin and gave the power spectrum dis5 played in Fig. 9.

The authors interpret the sodium record as one of marine aerosol deposition to Princess Elizabeth Land and suggest that it is related to the polar vortex, i.e. a persistent large-scale cyclonic circulation pattern in the middle and upper troposphere and the stratosphere, centered generally in the polar regions of each hemisphere. In

10 view of the dominant period of 21.1 years found in the data, they consider the sodium record, and indirectly the polar vortex to be related to the Hale cycle. If true, this is a signal directly related to climate.

\subsection{Varves}

Yet another indication for the 22-year cycle comes from varves, i.e. pairs of thin layers 15 of sediment. The first varve layer is usually light and composed of sand, pollen, and spores, while the second layer is dark and composed of fine clay particles, and they are formed by seasonal variations in sedimentary deposition. The lighter band is deposited during summer when a stronger water flow in nearby rivers transports coarse, sandy material into a lake. The larger particles settle rather quickly, while due the winds acting on the surface of the lake the fine clay is kept in suspension. In winter, when the lake freezes over, the effect of the winds on the lake surface is absent, and the clay particles slowly settle. There is, therefore, typically one varve per year, and one can easily determine the age of a varve formation.

After studying such varves in a Canadian Lake and in Precambrian limestone in 25 South Africa, is has been suggested already four decades ago by Anderson and Koopmans (1963) that the 20-25 year periodicity found in the varve thicknesses is related to the Hale cycle. An example for a more recent study by Livingstone and Hajdas (2001)

Solar or cosmic ray climate forcing?

H. Fichtner et al.

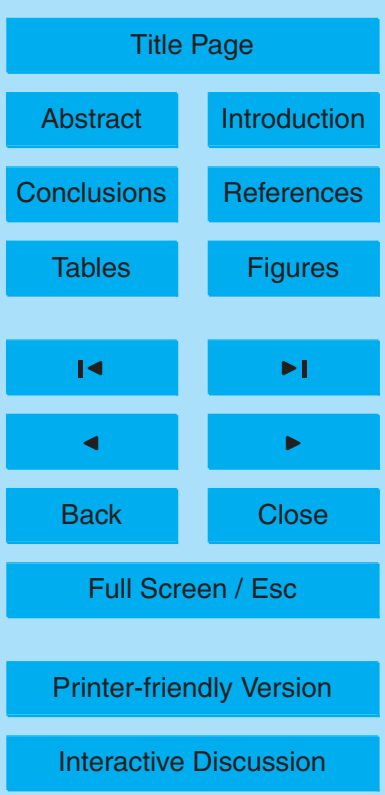


based on varve data obtained from a Swiss lake is shown in Fig. 9.

They indeed detected a 24.4-year peak in the periodogram, i.e. one close to the Hale cycle. While again not ultimately convincing, it is remarkable that varves located all over the world (for more examples see references in Livingstone and Hajdas, 2001) do posses an approximate Hale period in their thicknesses.

\section{Discussion and conclusion}

All in all, there appears to be quite some evidence for manifestations of the 22-year cycle of solar activity in terrestrial climate indicators as the above examples of clouds, rainfalls, droughts, glacio-chemicals, and varves are illustrating. We feel that our claim that the Hale cycle is very suitable to discriminate between solar irradiance and cosmic ray climate forcing deserves further research.

We want to stress that we do not claim that the climate is actually influenced by cosmic rays, we merely identify a criterion that allows one to distinguish between both forcings. If the presence of the Hale cycle in climate archives can indeed be confirmed,

15 it will be a strong argument in favour of cosmic ray forcing. Note also, that we do not consider other forcings, which might also influence the climate, like the anthropogenic influence.

Note that our criterion is not based on a correlation analysis alone. A 22-year cycle must be present in the climate data if cosmic rays are an external driver, because there 20 is a well-understood and well-observed physical process (drift) that gives rise to such period in cosmic ray fluxes. This period is not expected for the solar irradiance because no process linking it to the magnetic field orientation is known.

Nonetheless, one can test solar irradiance reconstructions (e.g. Lean et al., 1995) for the presence of a 22-year period. This was recently done by Lohmann et al. (2004)

with the result shown in Fig. 11. Obvioulsy, the 22-year signal in solar irradiance is marginally visible, which is not surprising in view of the reconstructed irradiance curve.

Even if, despite the above discussion, a strong 22-year period in solar irradiance

Solar or cosmic ray climate forcing?

\section{H. Fichtner et al.}

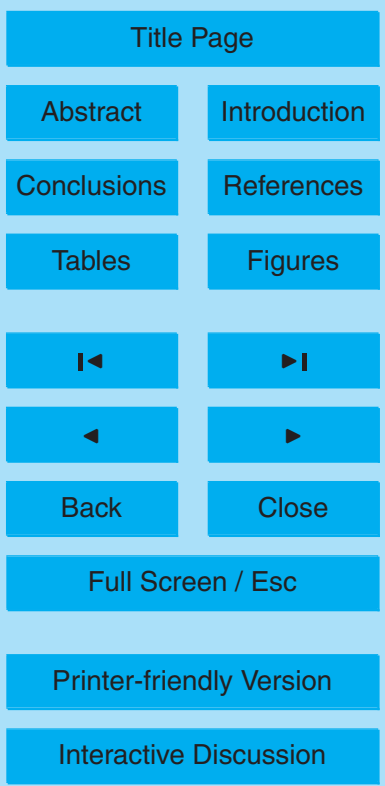


would be identified, there would still be hope for a discrimination of the two forcings. This is because the Hale cycle manifests in different cosmic ray flux maxima and not in the flux minima. If any effect of the magnetic field orientation in irradiance existed, one should expect it to show up in different irradiance maxima, as the presently available 5 data suggest that the irradiance during activity minimum varies far less than during activity maximum. If, despite the present absence of evidence, such periodicity would be found, it would imply a phase shift in the forcings by 11-years.

So, in conclusion, we are convinced that the Hale cycle provides a useful criterion to discriminate between (direct) solar irradiance and (indirect) cosmic ray forcing. The 10 presence of a 22-year periodicity can not only be understood on well-known physical grounds, but must be expected if cosmic rays do play a role in climate driving. Therefore, a successful test of whether 22-year periodicities in climate indicators are present or not is a promising tool to bring the presently intensely led debate to a satisfactory conclusion.

15 Acknowledgements. H. Fichtner is grateful to the organizers of the SORCE workshop in Durango, Colorado, USA, that took place in September 2005 and during which parts of the above considerations were presented. We acknowledge support of the research by the Deutsche Forschungsgemeinschaft (DFG) via the project "Heliocauses" carried out within the framework of the DFG priority program 1176 within CAWSES. We thank A. Kopp for his helpful comments on the manuscript.

\section{References}

Alexander, W. J. R.: Development of a multi-year climate prediction model, Water SA, 31, 209216, 2005. 10819

Anderson, R. Y. and Koopmans, I. H.: Harmonic analysis of varve time series, J. Geophys. Res., 68, 877-893, 1963. 10820

Beer, J., Long-term indirect indices of solar variability, Space Sci. Rev., 94, 53-66, 2000. 10817 Burroughs, W. J.: Weather Cycles, Cambridge University Press, 2004. 10819

Solar or cosmic ray climate forcing?

H. Fichtner et al.

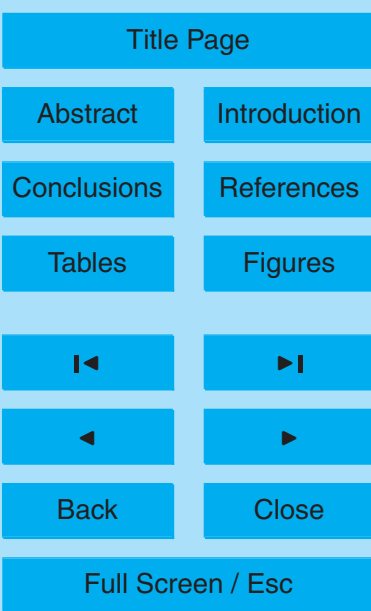

Printer-friendly Version

Interactive Discussion 
Caballero-Lopez, R. A., Moraal, H., McCracken, K. G., and McDonald, F. B.: The heliospheric magnetic field from 850 to 2000 AD, J. Geophys. Res., 109, A12102, doi:10.1029/2004JA010633, 2004. 10814

Christl, M., Mangini, A., Holzkämper, S., and Spötl, C.: Evidence for a link between the flux of galactic cosmic rays and Earth's climate during the past 200000 years, J. Atmos. Sol.-Terr. Phys., 66, 313-322, 2004. 10812

Eddy, J. A.: The Maunder Minimum, Science, 192, 1189-1202, 1976. 10812

Ferreira, S. E. S. and Potgieter, M. S.: Long-Term Cosmic-Ray Modulation in the Heliosphere, The Astrophys. J., 603, 744-752, 2004. 10816

10 Fichtner, H.: Anomalous Cosmic Rays: Messengers from the Outer Heliosphere, Space Sci. Rev., 95, 639-754, 2001. 10829

Fisk, L. A.: An overview of the transport of galactic and anomalous cosmic rays in the heliosphere: theory, Adv. Space Res., 23, 415-423, 1999. 10816

Fligge, M. and Solanki, S. K.: The solar spectral irradiance since 1700, Geophys. Res. Lett., 14, 2157-2160, 2000. 10815

Fröhlich, C. and Lean, J.: The Sun's Total Irradiance: Cycles, Trends and Related Climate Change Uncertainties since 1976, Geophys. Res. Lett., 25, 4377-4380, 1998. 10826

Harrison, R. G. and Stephenson, D. B.: Empirical evidence for a nonlinear effect of galactic cosmic rays on clouds, Proc. Roy. Soc. A, 462, 2068, doi:10.1098/rspa.2005.1628, 2005. $20 \quad 10813$

Heber, B.: Propagation and modulation of cosmic rays in the heliosphere, Plasmas in the laboratory and in the universe: New Insights and New Challenges, AIP Conf. Proc., 703, 111-122, 2004. 10829

Isenberg, P. A. and Jokipii, J. R.: Gradient and curvature drifts in magnetic fields with arbitrary spatial variation, Astrophys. J., 234, 746-752, 1979. 10816

Kopp, G., Lawrence, G., and Rottman, G.: Total Irradiance Monitor Design and On-Orbit Functionality, SPIE Proc., 5171-4, 14-25, 2003. 10827

Lean, J., Beer, J., and Bradley, R.: Reconstruction of solar irradiance since 1610: Implications for climate change, Geophys. Res. Lett., 22, 3195-3198, 1995. 10821, 10836

30 Livingstone, D. M. and Hajdas, I.: Climatically relevant periodicities in the thicknesses of biogenic carbonate varves in Soppensee, Switzerland (9740-6870 calendar yr BP), J. Paleolimn., 25, 17-24, 2001. 10820, 10821, 10835

Lohmann, G., Rimbu, N., and Dima, M.: Climate signature of solar irradiance variations: anal-

Solar or cosmic ray climate forcing?

H. Fichtner et al.

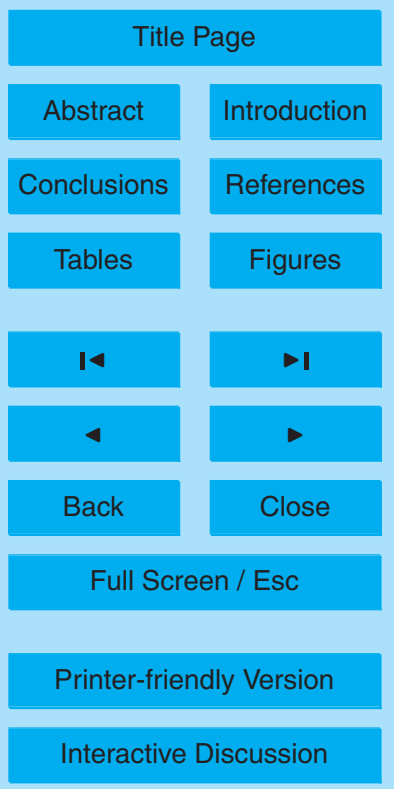

EGU 
ysis of long-term instrumental, historical, and proxy data, Int. J. Climatol., 24, 1045-1056, 2004. 10821, 10836

Board in Global Change, Commission on Geosciences, Environment and Resources, National Research Council, Solar Influences on Global Change, National Academy Press, Washing5 ton, 1994. 10812

Makarov, V. I. and Tlatov, A. G.: Polar Magnetic Field Reversals of the Sun in Maunder Minimum, J. Astrophys. Astron., 21, 193-196, 2000. 10818

Marsh, N. and Svensmark, H.: Galactic cosmic ray and El Nio-Southern Oscillation trends in International Satellite Cloud Climatology Project D2 low-cloud properties, J. Geophys. Res.,

10 108, AAC 6-1, 4195, doi:10.1029/2001JD001264, 2003. 10818, 10831

Mitchell Jr., J. M., Stockton, C. W., and Meko, D. M.: Evidence of a 22-year rhythm of drought in the western United States related to the Hale solar cycle since the 17th century, in: SolarTerrestrial Influences in Weather and Climate, edited by: McCormac, B. M., Seliga, T. A., and Reidel, D., 125-144, 1979. 10819

Miyahara, H., Masudaa, K., Menjoa, H.,Kuwanaa, K., Murakia, Y., and Nakamurab, T.: Variation of the cosmic ray intensity during the Maunder Minimum deduced from carbon-14 content in tree rings, Proc. 29th Int. Cosmic Ray Conf., Aug 2-10, Pune, India, paper in SH 3.4. 10817, 10830

Murphy, J. O., Sampson, H., Veblen, T. T., and Villalba, R.: Regression model for the 22-year 20 Hale solar cycle derived from high altitude tree-ring data, Proc. Astron. Soc. Australia, 11, 157-163, 1994. 10818, 10819

Olsen, P. E. and Kent, D. V.: Long-period Milankovitch cycles from the Late Triassic and Early Jurassic of eastern North America and their implications for the calibration of the Early Mesozoic time-scale and the long-term behaviour of the planets, Phil. Trans. Roy. Soc. A, 357, 1761-1786, 1999. 10812

Parker, E. N.: The passage of energetic charged particles through interplanetary space, Planet. Space Sci., 13, 9, 1965. 10815

Perry, C.: Midwestern streamflow, precipitation, and atmospheric vorticity influenced by pacific sea-surface temperatures and total solar-irradiance variations Int. J. Climatology, 26, 207$30 \quad 218,2005.10819$

Raspopov, O. M., Dergachev, V. A., and Kolström, T.: Hale cyclicity of solar activity and its relation to climate variability, Sol. Phys., 224, 455-463, 2004. 10818

Rigozo, N. R., Nordeman, D. J. R., Echer, E., Vieira, L. E. A., Echer, M. P. S., and Prestes,

\section{Solar or cosmic ray climate forcing?}

\section{H. Fichtner et al.}

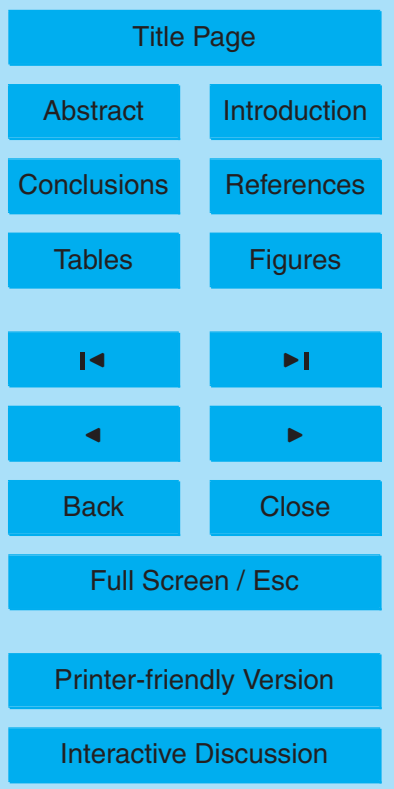


A.: Tree-ring width wavelet and spectral analysis of solar variability and climatic effects on a Chilean cypress during the last two and a half millennia, Climate Past Discuss., 1, 121-135, 2005. 10818, 10832

Rind, D.: The Sun's Role in Climate Variations, Science 296, 673-677, 2002. 10813

5 Scherer, K. and Fichtner, $\mathrm{H}$.: Constraints on the heliospheric magnetic field variation during the Maunder Minimum from cosmic ray modulation modelling, Astron. Astrophys., 413, L11-14, 2004. 10814

Scherer, K., Fahr, H.-J., Fichtner, H., Heber, B., Long-Term Modulation of Cosmic Rays in the Heliosphere and its Influence at Earth, Sol. Phys. 224, 305-316, 2004

10 Shaviv, N. and Veizer, J.: Celestial Driver of Phanerozoic Climate?, GSA Today, 13, 4, 2003. 10812, 10813

Stager, J. C., Ryves, D., Cumming, B. F., Meeker, L. D., and Beer, J.: Solar variability and the levels of Lake Victoria, East Africa, during the last millenium, J. Paleolimnol., 33, 243-251, 2005. 10819

Stuiver, M., Reimer, P. J., and Braziunas, T. F.: High-precision radiocarbon age calibration for terrestrial and marine samples, Radiocarbon 40, 1127, 1998. 10830

Svensmark, H.: Influence of Cosmic Rays on Earth's Climate, Phys. Rev. Lett., 81, 5027-5030, 1998. 10826

Valdes-Galicia, J. F., Velasco, V. M., and Mendoza, B.: Mid Term Cosmic Ray Quasi Periodicities And Solar Magnetic Activity Manifestations, Proc. 29th Int. Cosmic Ray Conf., Aug 2-10, Pune, India, paper in SH 3.4. 10814

van Loon, H. and Shea, D. J.: The global 11-year solar signal in July-August, Geophys. Res. Lett., 27, 2965-2968, 2000. 10812

Xiao, C., Mayewski, P. A., Qin, D., Li, Z., Zhang, M., and Yan, Y.: Sea level pressure variability over the southern Indian ocean inferred from a glaciochemical record in Princess Elizabeth Land, east Antarctica, J. Geophys. Res., 109, D16101, doi:10.1029/2003JD004065, 2004 10820, 10834

Zhao, J., Han, Y.-B., and Li, Z.-A.: The Effect of Solar Activity on the Annual Precipitation in the Beijing Area, Chin. J. Astron. Astrophys., 4, 189-197, 2004 10819, 10833

Solar or cosmic ray climate forcing?

\section{H. Fichtner et al.}

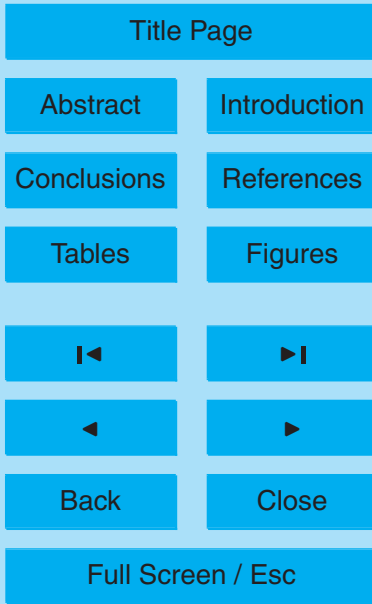

Printer-friendly Version

Interactive Discussion 


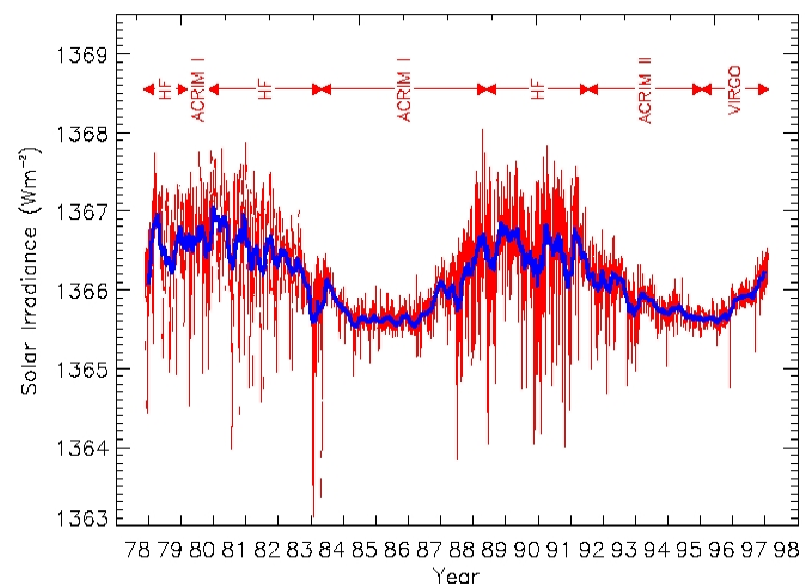

\section{ACPD}

6, 10811-10836, 2006

\section{Solar or cosmic ray climate forcing?}

\section{H. Fichtner et al.}
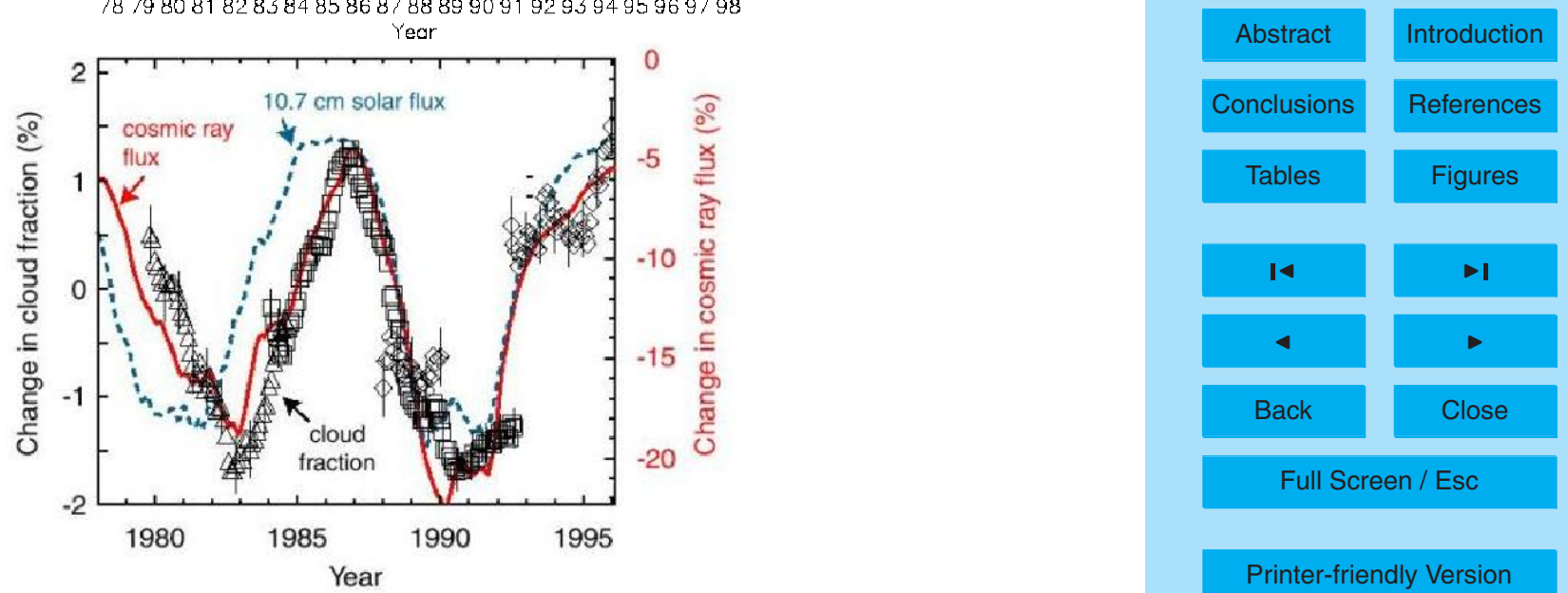

Printer-friendly Version

Interactive Discussion

Fig. 1. Time series of the solar irradiance (upper panel) the cosmic ray flux and the terrestrial cloud cover (both in lower panel), taken from Fröhlich and Lean (1998) and Svensmark (1998), respectively. 


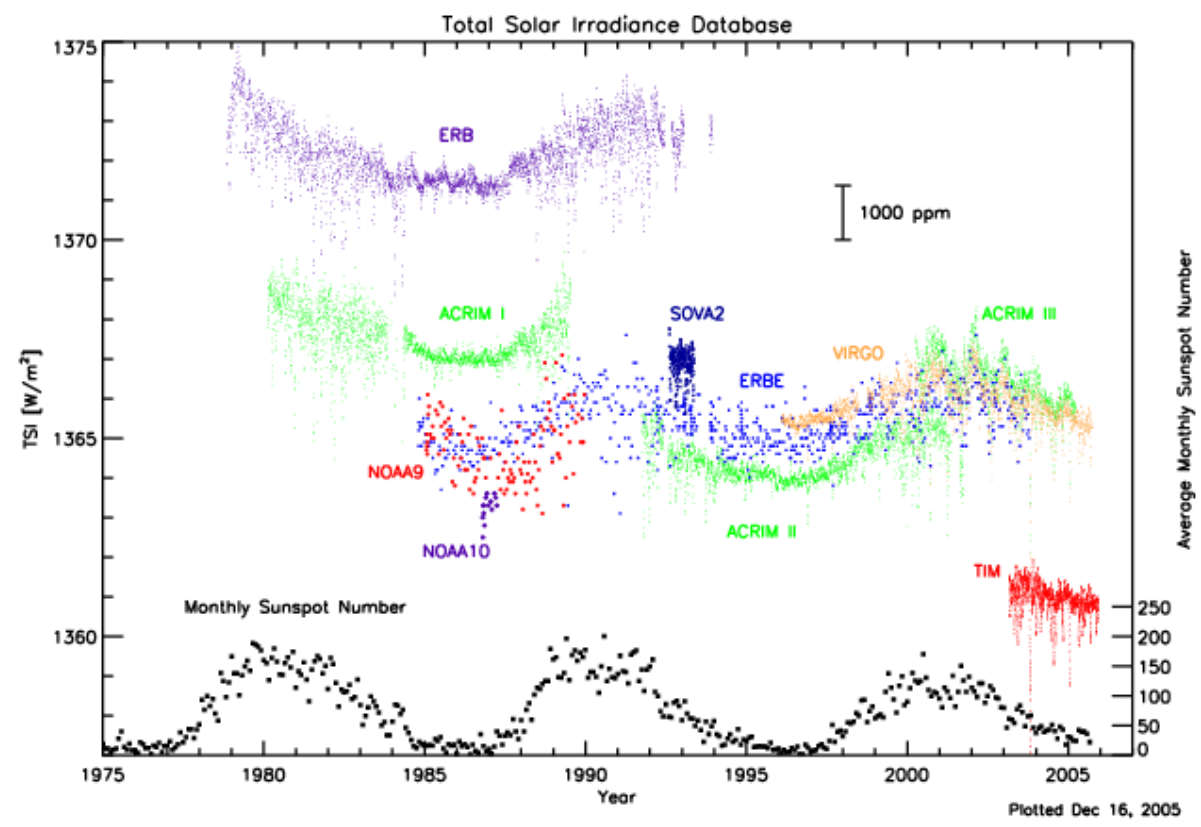

Fig. 2. Overlapping measurements from several space-borne instruments have given an uninterrupted record of the total solar irradiance since 1978, taken from Kopp et al. (2003), see also references therein. Data are from the Earth radiation budget experiments (ERB, ERBE), the active cavity radiometer irradiance monitors (ACRIM), two solar monitors of the National Oceanic and Atmospheric Administration (NOAA), the solar variability experiment (SOVA), the variability of solar irradiance and gravity oscillations experiment (VIRGO) and the total irradiance monitor (TIM). A corresponding database is maintained at http://spot.colorado.edu/ koppg/TSI/.

\section{ACPD}

6, 10811-10836, 2006

Solar or cosmic ray climate forcing?

\section{H. Fichtner et al.}

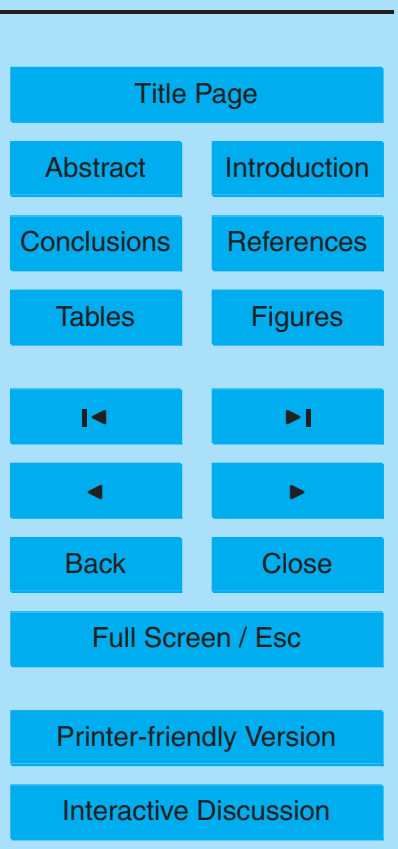




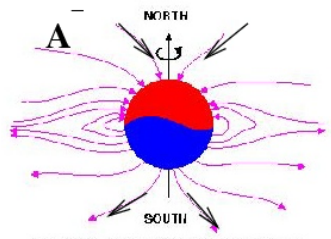

CORONAL HAGHETIC FIELD LINES AT
HEXT SOLAR MINIMUM

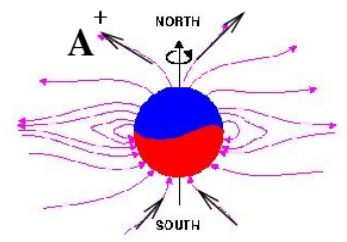

CORONAL MAGHETIC FIELD LINES AT SOLAR MIHIN UM ACTIVITY

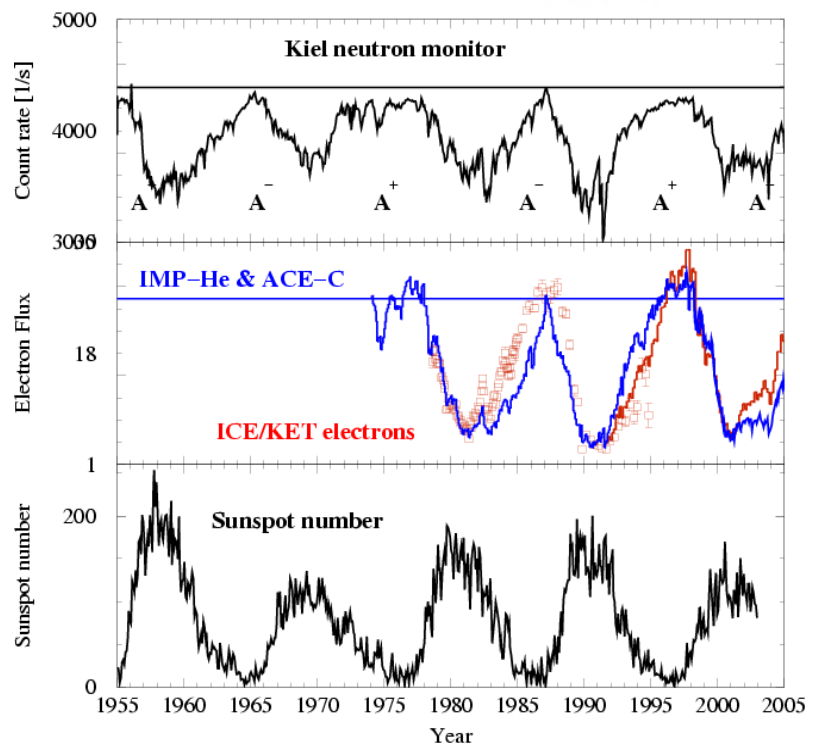

Fig. 3. The 22-year cycle in cosmic ray fluxes as observed with terrestrial neutron monitors (top panel) and with the IMP, ACE and Ulysses spacecraft (middle panel) is clearly visible in the alternating less and more peaked maxima coinciding with the minima in the sunspot number (bottom panel). The horizontal lines in the top and middle panel emphasise the different peak heights and, therefore, different fluxes and spectra during two consecutive minima.

\section{ACPD}

6, 10811-10836, 2006

Solar or cosmic ray climate forcing?

\section{H. Fichtner et al.}

Title Page

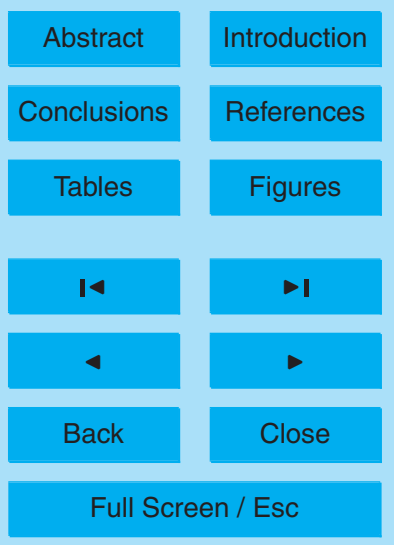

Printer-friendly Version

Interactive Discussion 

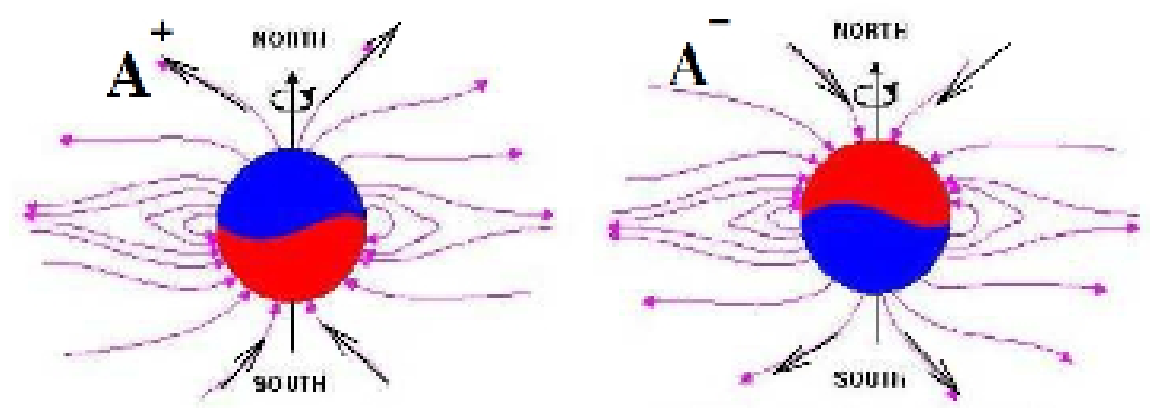

ACPD

6, 10811-10836, 2006
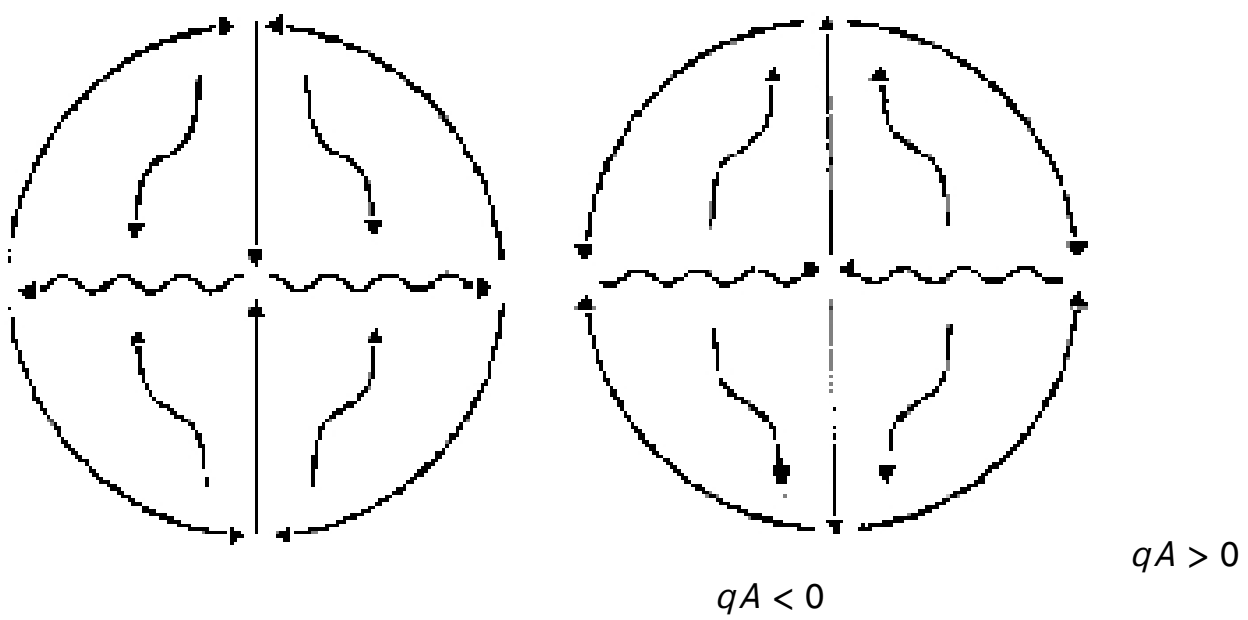

Solar or cosmic ray climate forcing?

\section{H. Fichtner et al.}

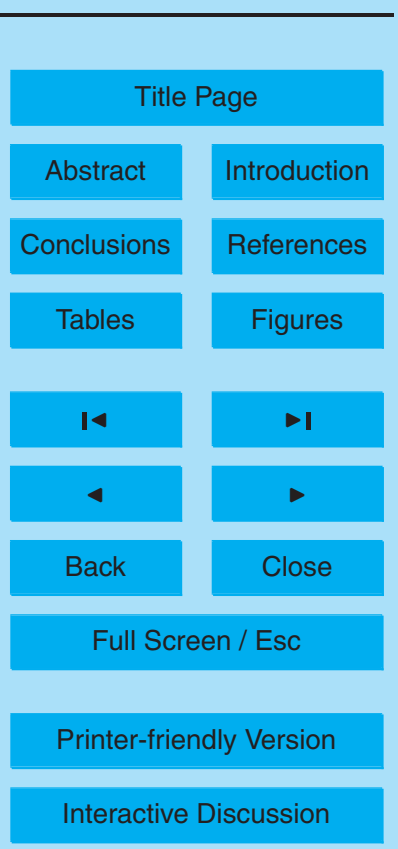

Fig. 4. For the two subcycles of the whole 22-year Hale cycle in the upper row, the corresponding drift patterns are given schematically in the lower row, taken from Heber (2004) and Fichtner (2001), respectively. 


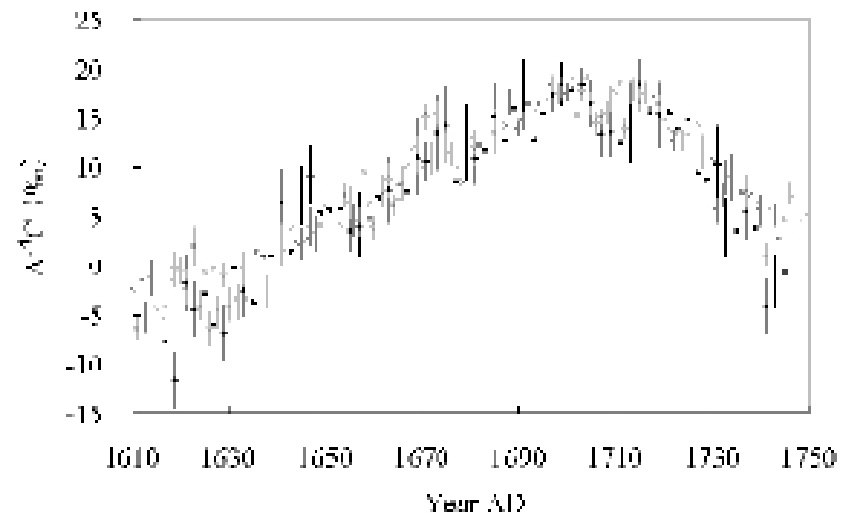

\section{ACPD}

6, 10811-10836, 2006

Solar or cosmic ray climate forcing?

\section{H. Fichtner et al.}

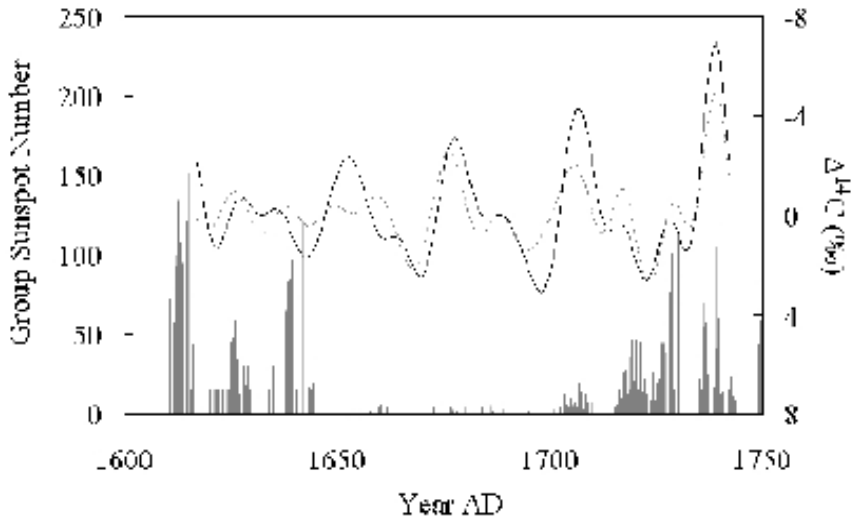

Title Page

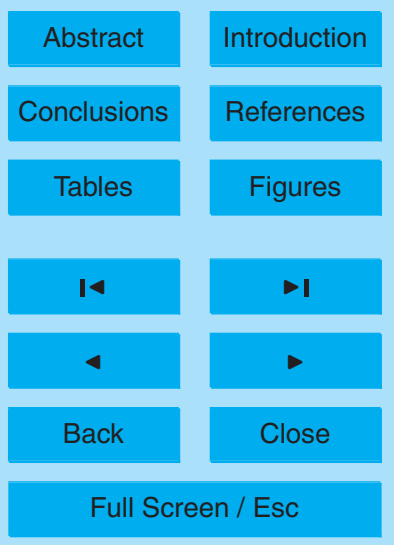

Fig. 5. The 22-year period in time series of ${ }^{14} \mathrm{C}$ during the Maunder Minimum of solar activity. The top panel shows the time series obtained from the tree rings. The bottom panel gives the monthly group sunspot activity and the band-pass filtered ${ }^{14} \mathrm{C}$ records with the bandwidth of 10-35 years (solid curve/dots from Miyahara et al., 2005 and dotted curve/circles from Stuiver et al., 1998). Note that the ${ }^{14} \mathrm{C}$ data are plotted inversely (taken from Miyahara et al., 2005). 


\section{ACPD}

6, 10811-10836, 2006
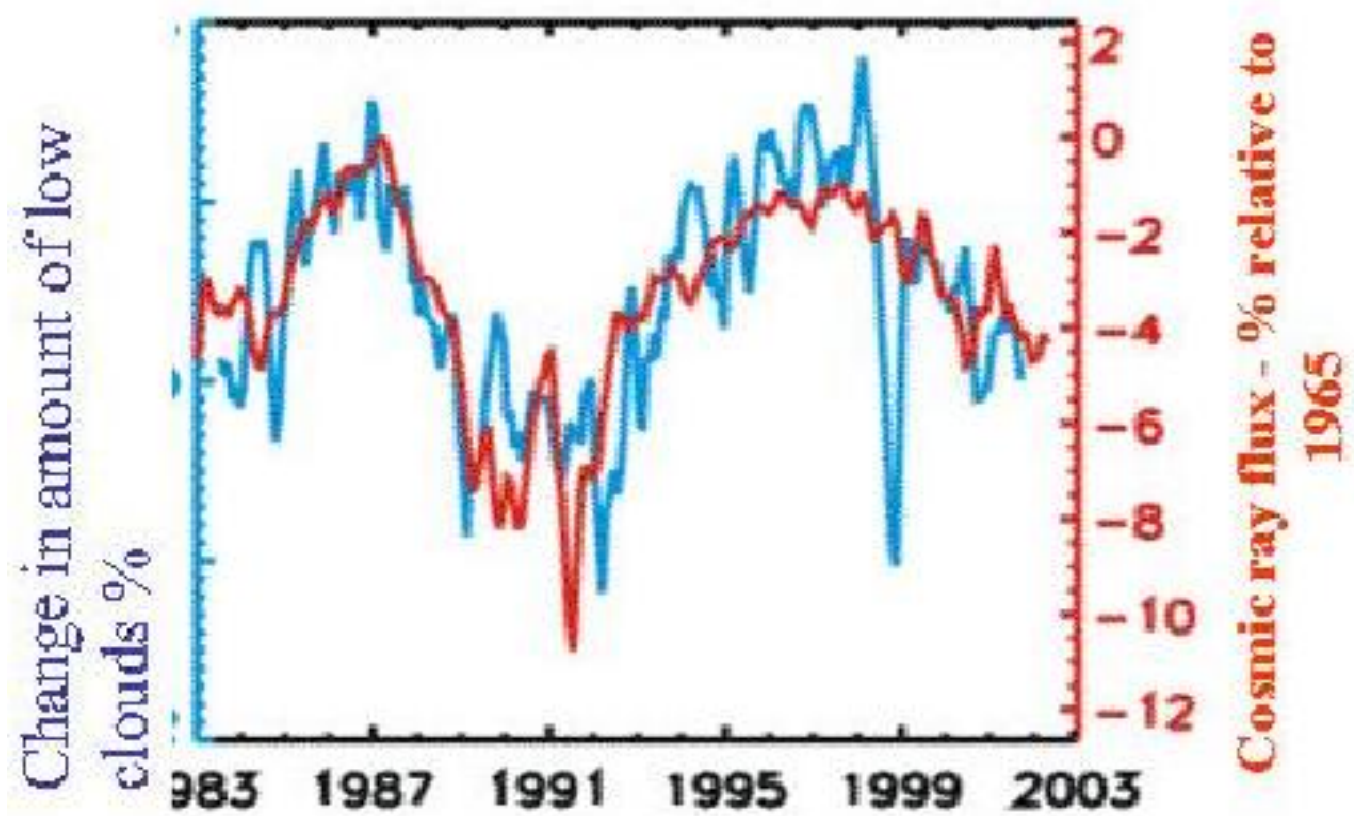

Fig. 6. Flat and peaked tops in the terrestrial (low) cloud coverage according to Marsh and Svensmark (2003).

\section{Solar or cosmic ray} climate forcing?

\section{H. Fichtner et al.}

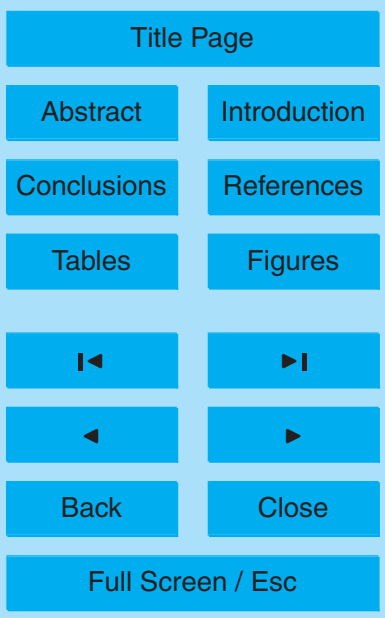

Printer-friendly Version

Interactive Discussion 


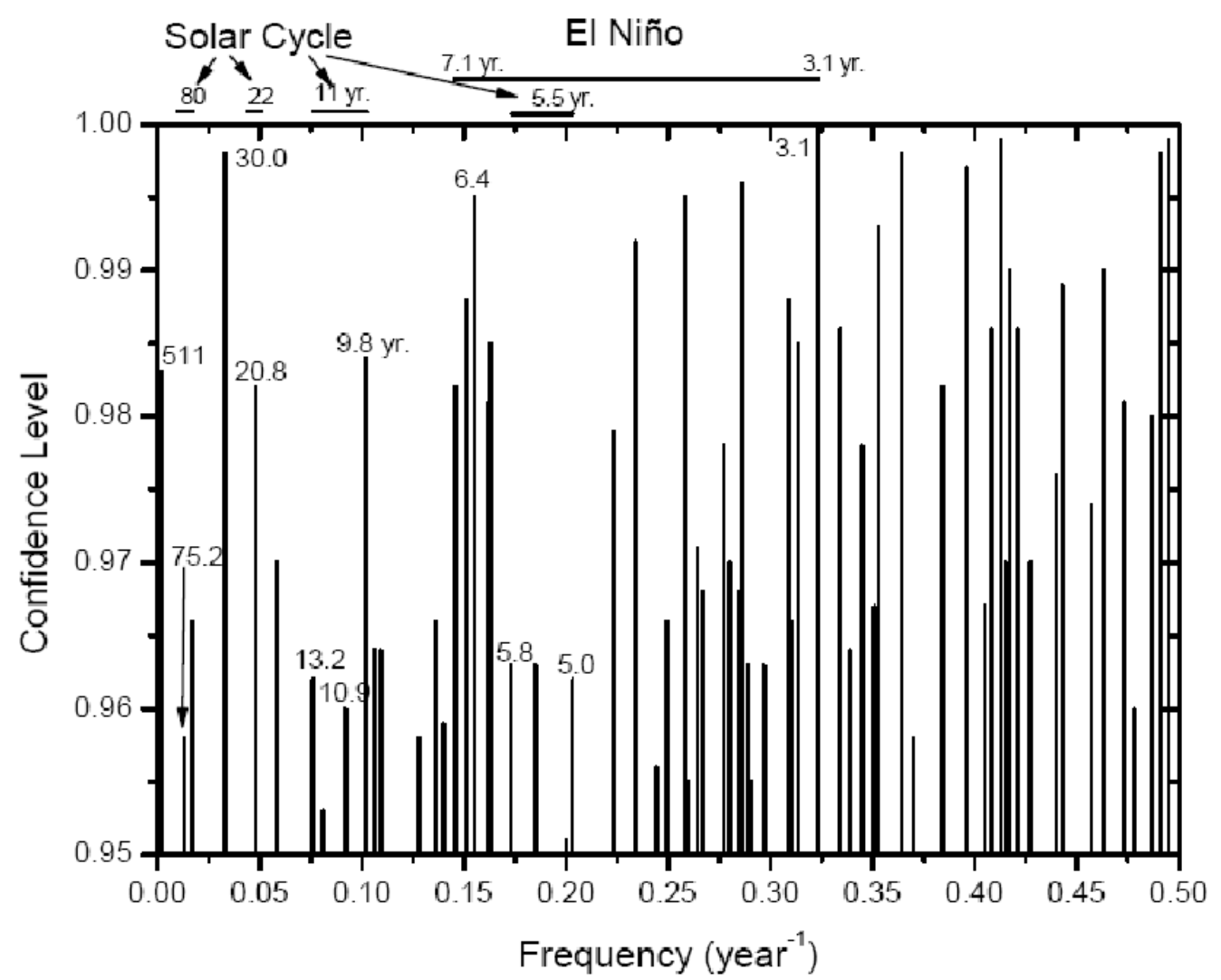

Fig. 7. Frequency multiple taper spectrum of the confidence level registered in the growth rings, above $95 \%$ of confidence level (taken from Rigozo et al., 2005).

\section{ACPD}

6, 10811-10836, 2006

Solar or cosmic ray climate forcing?

\section{H. Fichtner et al.}

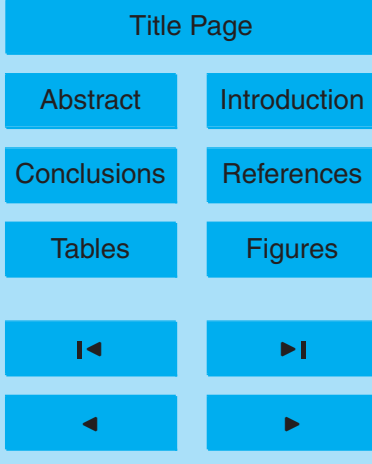

Back

Close

Full Screen / Esc

Printer-friendly Version

Interactive Discussion 


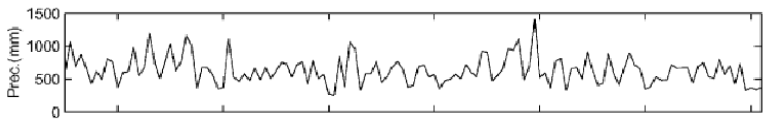

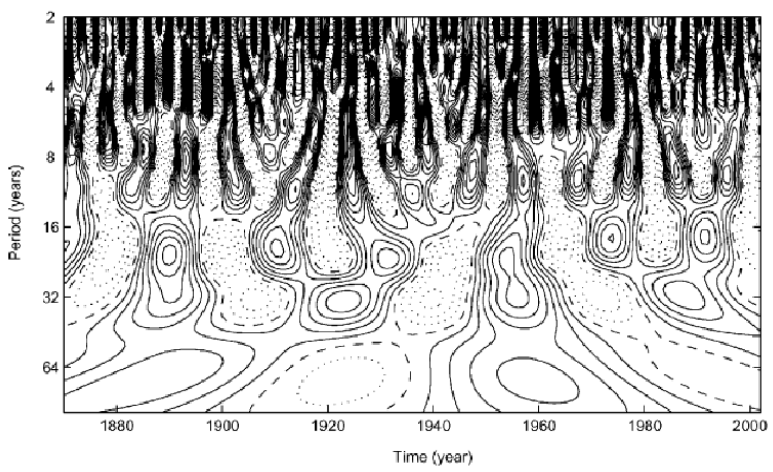

6, 10811-10836, 2006

Solar or cosmic ray climate forcing?

\section{H. Fichtner et al.}
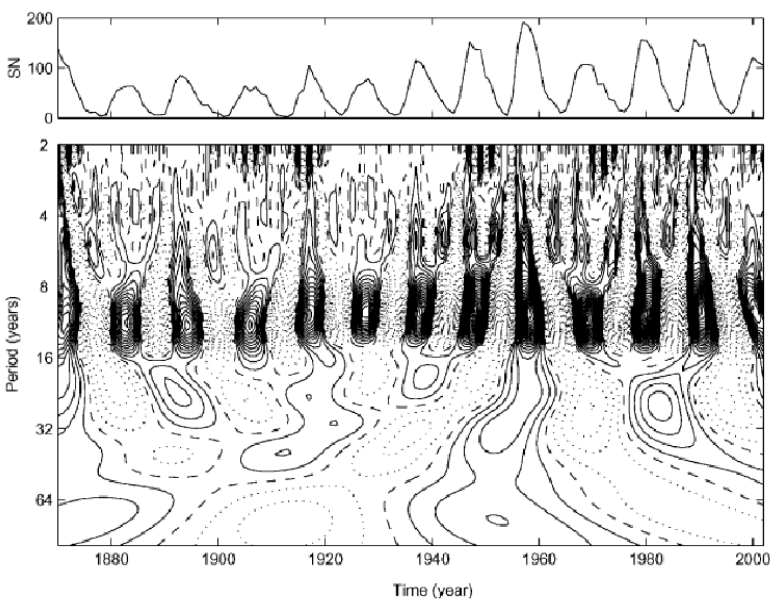

Title Page

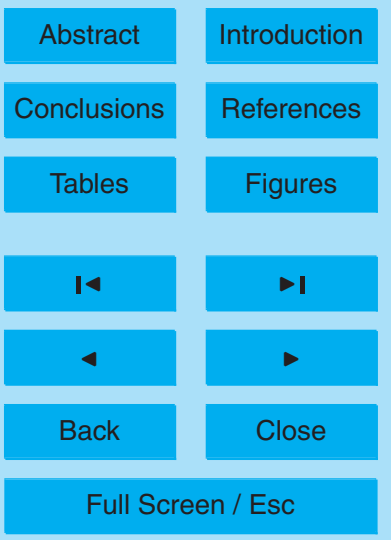

Printer-friendly Version

Interactive Discussion

Fig. 8. Wavelet analysis of annual precipitation in the Beijing area (upper panel) and the sunspot number (lower panel), taken from Zhao et al. (2004). 


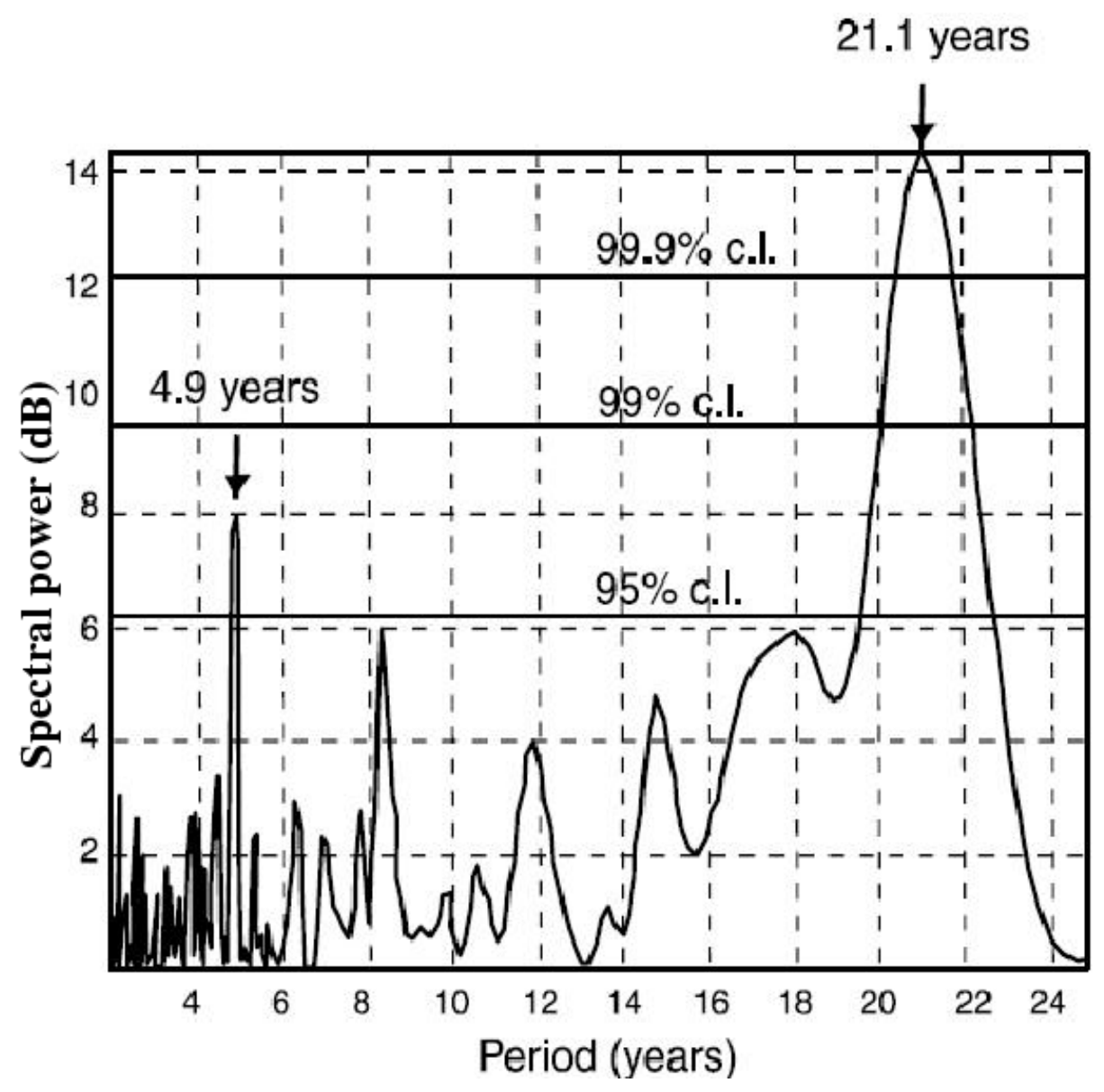

Fig. 9. The power spectrum from the sodium record for the period 1745-1996, taken from Xiao et al. (2004).

\section{ACPD}

6, 10811-10836, 2006

Solar or cosmic ray climate forcing?

\section{H. Fichtner et al.}

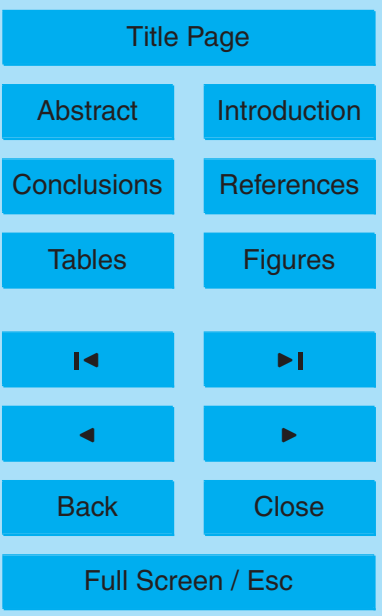

Printer-friendly Version

Interactive Discussion 


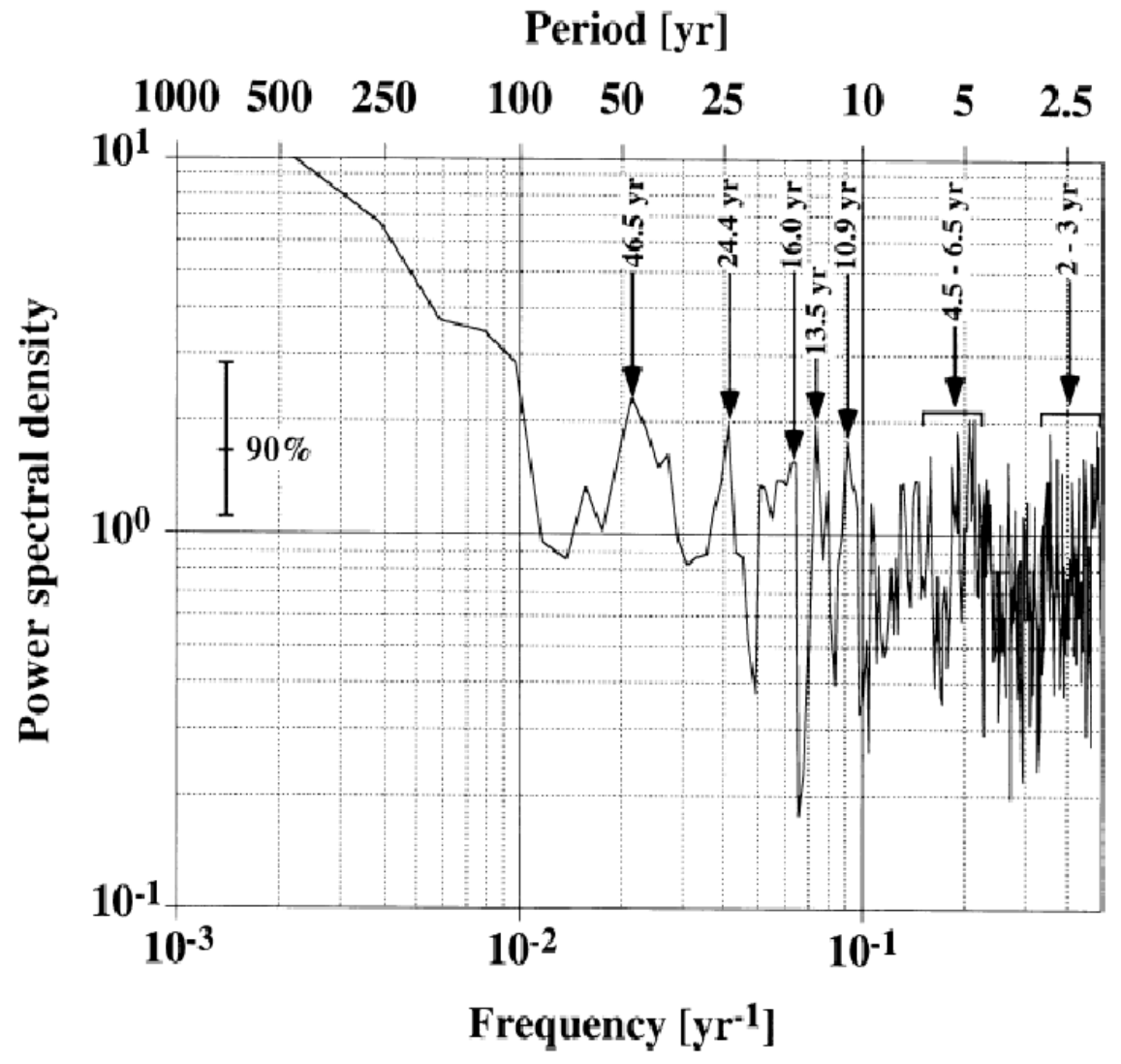

Fig. 10. Power spectrum of varve thicknesses from Soppensee Switzerland, $9740-6870$ calendar yr before present. Of the 15 most pronounced peaks, the first five are labelled individually, whilst the higher frequency peaks are divided into two labelled groups. The $90 \%$ confidence interval is shown on the left, taken from Livingstone and Hajdas (2001).

\section{ACPD}

6, 10811-10836, 2006

Solar or cosmic ray climate forcing?

\section{H. Fichtner et al.}

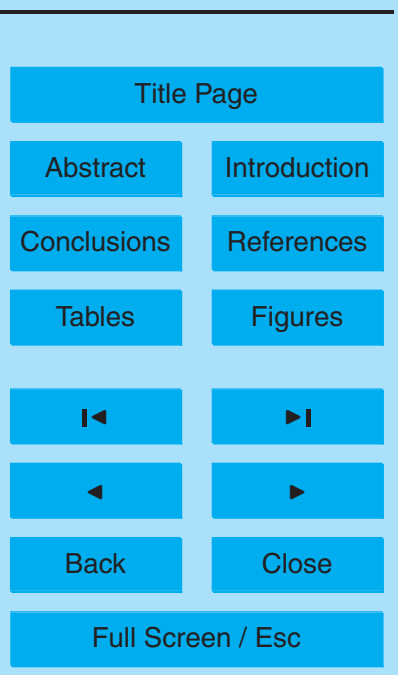

Printer-friendly Version

Interactive Discussion 


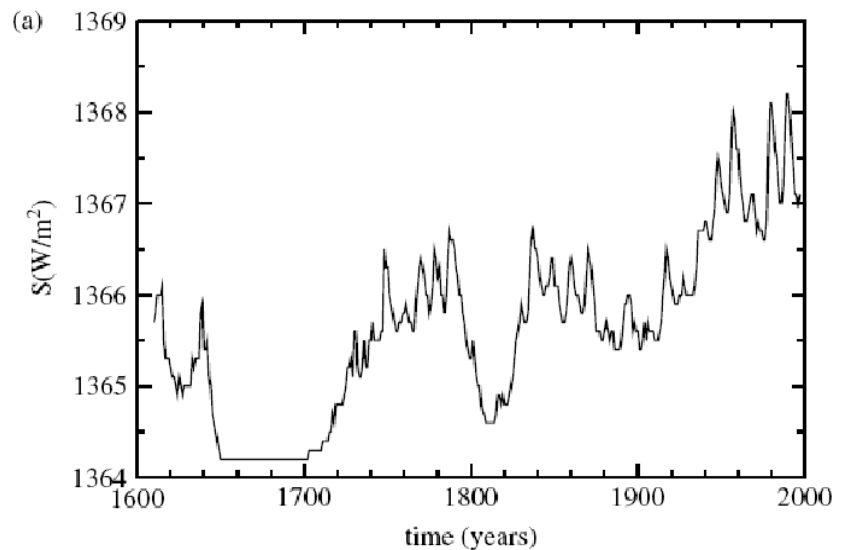

\section{ACPD}

6, 10811-10836, 2006

\section{Solar or cosmic ray climate forcing?}

\section{H. Fichtner et al.}

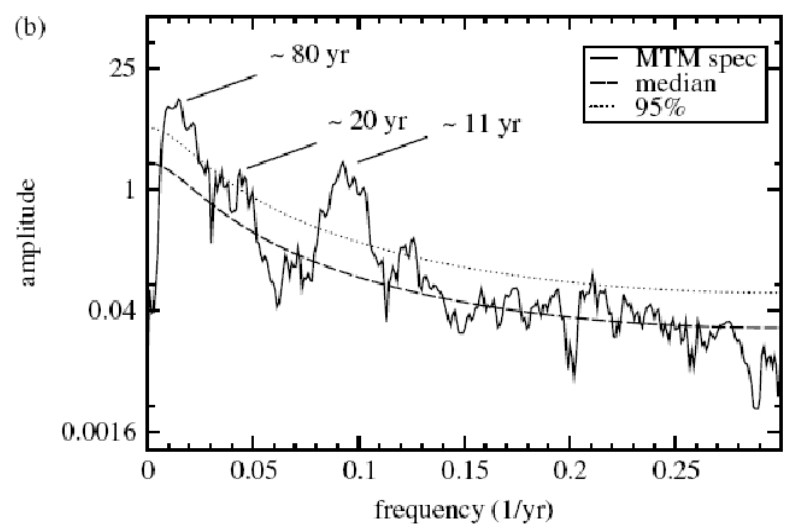

Title Page

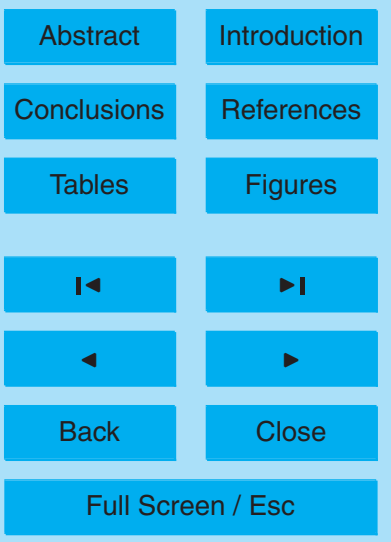

Printer-friendly Version

Interactive Discussion

Fig. 11. Upper panel: Time series of solar irradiance $(S)$ according to the reconstruction by Lean et al. (1995). Lower panel: The power spectrum of the detrended solar irradiance time series represented in (a), obtained by Lohmann et al. (2004) with the multiple taper method. 